\title{
Ante la cementización de la vida: ;Vamos a la playa!
}

\section{Faced with the cementization of life: $¡$ Vamos a la playa!}

\author{
Azul Martina Blaseotto \\ Universidad del Museo Social Argentino
}

Azul Blaseotto (1974, Buenos Aires) es artista visual, ensayista y educadora. Master of Arts por la Universität der Künste Berlin, Profesora de Pintura por la Universidad Nacional del Arte de Buenos Aires. Manteniendo un enfoque basado en la investigación con métodos artísticos y la práctica de dibujo documental en contexto, explora y documenta procesos socioculturales vinculados al territorio, los derechos humanos y los derechos de la naturaleza bajo el paradigma del extractivismo. Trabaja con diversos medios, como el cómic, la pintura, la instalación, la intervención performática y la publicación. Es cofundadora del colectivo de investigación y experimentación artístico-activista «Plataforma La Dársena». Desde 2010 registra dibujísticamente los juicios por crímenes de lesa humanidad en Argentina. Su primera novela gráfica, Vamos a la playa, fue publicada en 2018. Ha recibido, entre otras distinciones, el Premio 8M/ 2021 del Ministerio de Cultura de Argentina y el Szenario Preis/ 2008 del Festival Internacional de Comix Fumetto. Sus obras se han mostrado en numerosas exposiciones individuales y colectivas desde 1997, entre otras: Museo Ludwig, Colonia; Documenta 12, Kassel y Theater Rampe, Stuttgart, Alemania; Teatro Nacional Cervantes; Centro Cultural Borges; Palais de Glace y Centro Cultural Kirchner, Buenos Aires; KODE 1, Bergen, Noruega; MACBA de Barcelona y Centre del Carme de Valencia, España; SUBTE, Montevideo; Museo de Arte Contemporáneo y Biblioteca Nacional, Santiago de Chile; Galerie Kornschütte, Lucerna, Suiza.

Fecha de recepción: 31 de octubre de 2021

Fecha de aceptación definitiva: 9 de diciembre de 2021 


\section{Resumen}

¿Cómo dibujar el mar, atmósfera nunca igual a sí misma e ingobernable? ¿Cuál es la memoria estética del territorio "playa»? ¿Qué operaciones antrópicas ponen en riesgo este territorio? Vamos a la playa es una invitación a pensar la especificidad de una geografía determinada dejando de lado la idea universal del litoral marítimo y viajando por las capas de su construcción política y social. En tiempos de cambio climático y crisis social, ecológica y ambiental, la novela gráfica retrata de manera descarnada el paraíso perdido al borde del mar ante el avance indiscriminado y suicida del desarrollo inmobiliario. Vamos a la playa tiene que ver no solo con la playa, sino con lo que de playa queda en un mundo dominado por la economía de mercado y la obsoletización permanente de la concepción «Estado de Bienestar». Se investiga el sustrato formal que permite un relato en clave geopolítica del territorio bonaerense marginal. La puesta en página, la variedad de composiciones gráficas y pictóricas, la inclusión de fotografías originales, las citas dibujadas a tomas fotográficas y a pinturas históricas son recursos que buscan explícitamente anclar el relato en un realismo de tipo documental, en paralelo a sostener operaciones discursivas ficcionales. En este ensayo reflexiono sobre las tensiones que marcan el hacer (proceso, búsqueda), tanto como el plano simbólico resultante (lo hecho).

Palabras clave:, cambio climático, cuaderno de dibujos, novela gráfica, realismo documental, territorio 


\begin{abstract}
How to draw the sea, an atmosphere never equal to itself and ungovernable? What is the aesthetic memory of the "beach" territory? What anthropic operations put this territory at risk? Vamos a la playa is an invitation to think about the specificity of a determined geography, leaving aside the universal idea of the maritime coastline and travelling through the layers of its political and social construction. In times of climate change and social, ecological and environmental crisis, this graphic novel portrays in a stark way the lost paradise by the sea in the face of the indiscriminate and suicidal advance of real estate development. Vamos a la playa is not only about the beach, but also about what remains of the beach in a world dominated by the market economy and the permanent obsoletisation of the "Welfare State" concept. The formal substratum that allows for a geopolitical narrative of the marginal territory of Buenos Aires territory is investigated. The page layout, the variety of graphic and pictorial compositions, the use of photographs and drawn reproductions of historical photographs and paintings are resources that explicitly seek to anchor the story in a documentary-like realism, in parallel to sustaining fictional discursive operations. On this essay I would like to reflect on the tensions that mark the making (process, search), as well as on the resulting symbolic plane (what is made).
\end{abstract}

Keywords: climate change, documentary realism, graphic novel, territory, sketchbook

\title{
Cita bibliográfica
}

Blaseotto, A. M. «Ante la cementización de la vida: ;Vamos a la playa!», en CuCo, Cuadernos de cómic, n. ${ }^{\circ} 17$ (2021), pp. 63-83. 


\section{Introducción}

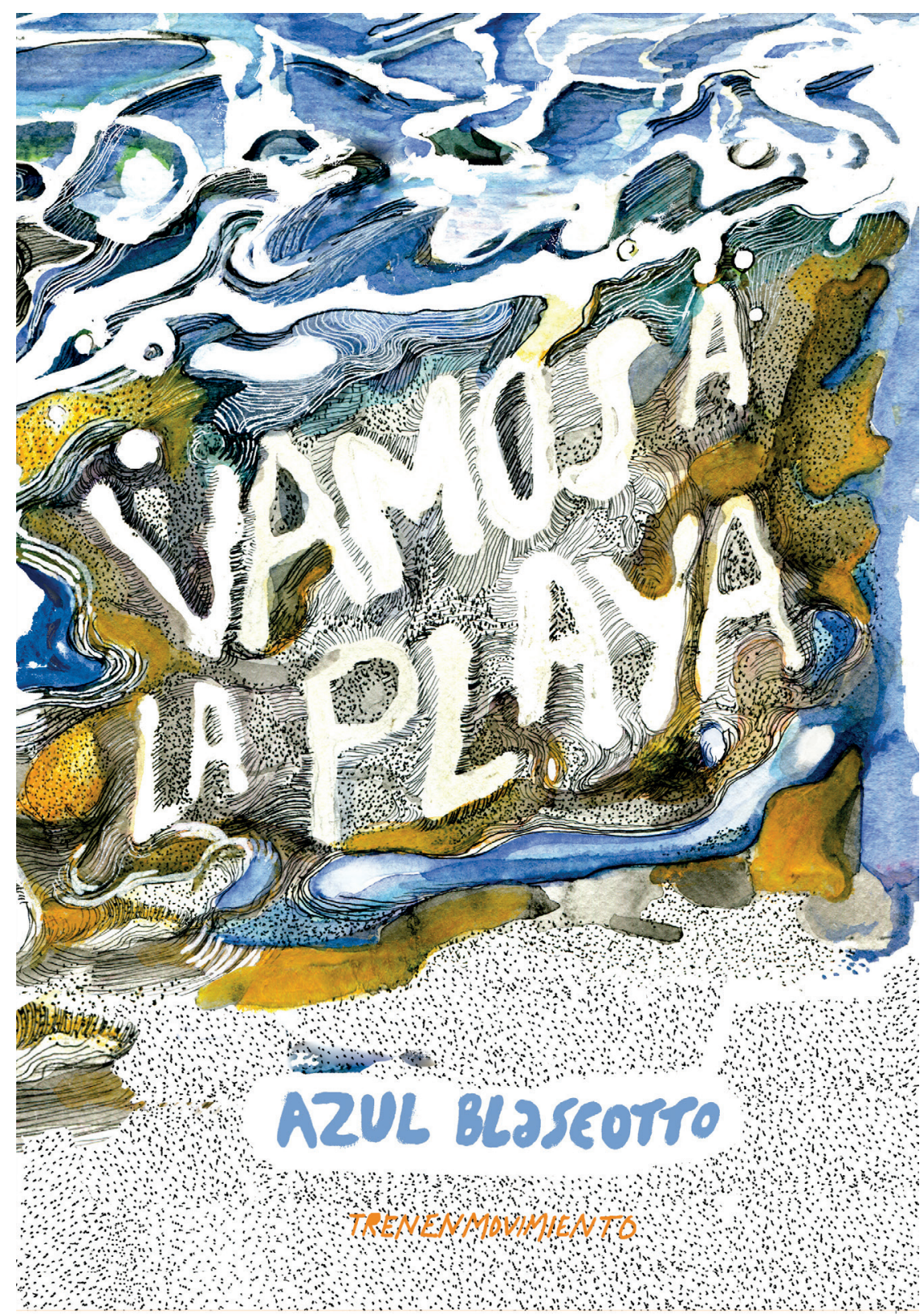

FIG. 1. Blaseotto, A. Vamos a la playa, 2018. Acuarela sobre papel. Diseño de la portada.

Al principio, siempre hay una imagen. La vida entra por los ojos y yo disfruto del poder de la visión. Mirar el mar es ver la extensión de la vida por donde corre el viento; así, la luz solar, la nocturna y la de la tormenta se reflejan infinitamente en ella. El olor a sal y yodo copa las narinas. Se es invencible y, a la vez, no se existe. Estar en la playa 
es formar parte de ese lugar acostado, el horizonte. ¿Dijimos que «al principio siempre hay una imagen»? Tal vez sea inexacto. Lo que hay es el color. El azul-turquesa donde se confunden agua y cielo. La imprecisión, la amplitud, lo silvestre y anárquico. Es un estado de ánimo atmosférico.

Vamos a la playa es una novela gráfica que pivota entre la especificidad de una geografía determinada en su cultura local y la idea universal del litoral marítimo, un acercamiento al paisaje que desde el siglo Xvir llamamos «playa». Este género pictórico, inventado por la academia europea, las ciencias sociales occidentales y las clases altas, ${ }^{1}$ es tratado en esta novela con un foco particular: la costa en cuestión es ubicable en el hemisferio sur y se desarrolla al márgen de las historias altisonantes. ${ }^{2}$

Vamos a la playa, nos tararea al oído Donald, un cantante popular. Promete un paraíso: «el mar es limpio y los peces no están heridos». ${ }^{3}$ Hoy, en tiempos de cambio climático y crisis social, ecológica y ambiental, sabemos que ese paraíso está definitivamente perdido. Nicolás Testoni prologa la novela y refiere a la actitud empecinada de volver a intentar recuperarlo:

No hay escapada a la playa que escape a la promesa de dar, por fin, con algún paraíso olvidado. Hacia él peregrinamos cada verano, sólo para descubrir que nuestra fisonomía es cada vez menos parecida a la de Adán o a la de Eva, que Edén no es más que el nombre de un buen negocio inmobiliario, y que en las arenas bonaerenses quedan pocas chances para «la vida descalzo», con tanto culo de botella agazapado. ${ }^{4}$

La historia, dibujada secuencialmente, sigue la hilación de los apuntes gráficos realizados in situ en mi cuaderno de viaje, durante las travesías por la costa de la provincia de Buenos Aires y sus balnearios populares. Santiago García Navarro bien dice en la contratapa que esta obra es una road movie, «una película de acción llena de furia». A la intensidad de las pasiones suele representárselas en las historietas como caricaturas. La exageración de los gestos y la síntesis gráfica son recursos populares al momento de emitir mensajes claros y contundentes. En esta novela no hay caricaturas, pero sí el intento de contagiar furia por el desastre cultural y natural en el que han sido trasformados los bordes del mar.

La simple decisión de ir de vacaciones se transforma desde el primer minuto en una interrogación acerca de las infraestructuras, las formaciones sociales, las estrategias políticas

\footnotetext{
${ }^{1}$ Hay una extensa bibliografía que estudia el tema. Al respecto pueden consultarse: Mitchell, W. J. T. Landscape and power. Chicago, University of Chicago, 1994; Aliata, F. y Silvestri, G. El paisaje como cifra de armonía. Buenos Aires, Nueva Visión, 2001.

2 Blaseotto, A. Vamos a la playa. Temperley, Tren en Movimiento, 2018.

3 Donald tiene una profusa produccion musical relativa a la playa.

${ }^{4}$ Blaseotto, A. (2018). Op. cit., p. 7.
} 
y los modelos económicos que construyen ese territorio y paisaje hoy cotidiano llamado playa. La provocación inicial es en torno del sistema ferroviario, hecha desde el tren al que acaban de subir los protagonistas. A lo que seguirán la política de tierras, la exclusión social, el exterminio de indígenas. ${ }^{5}$

Si al principio hay las sensaciones y percepciones estéticas, la pura emoción y contemplación, durante el transcurrir de la lectura nos asaltan la curiosidad y la intelectualización de aquello que nos convoca emocionalmente. ¿Sobre qué capas está construido este paisaje? ¿Qué operaciones antrópicas lo ponen en riesgo? ¿Cuál es la historia personal de este territorio? ¿Cómo dibujar el mar, atmósfera nunca igual a sí misma e ingobernable? Vamos a la playa es, en definitiva, una provocación artística a compartir estos y más interrogantes.

\section{El tren}

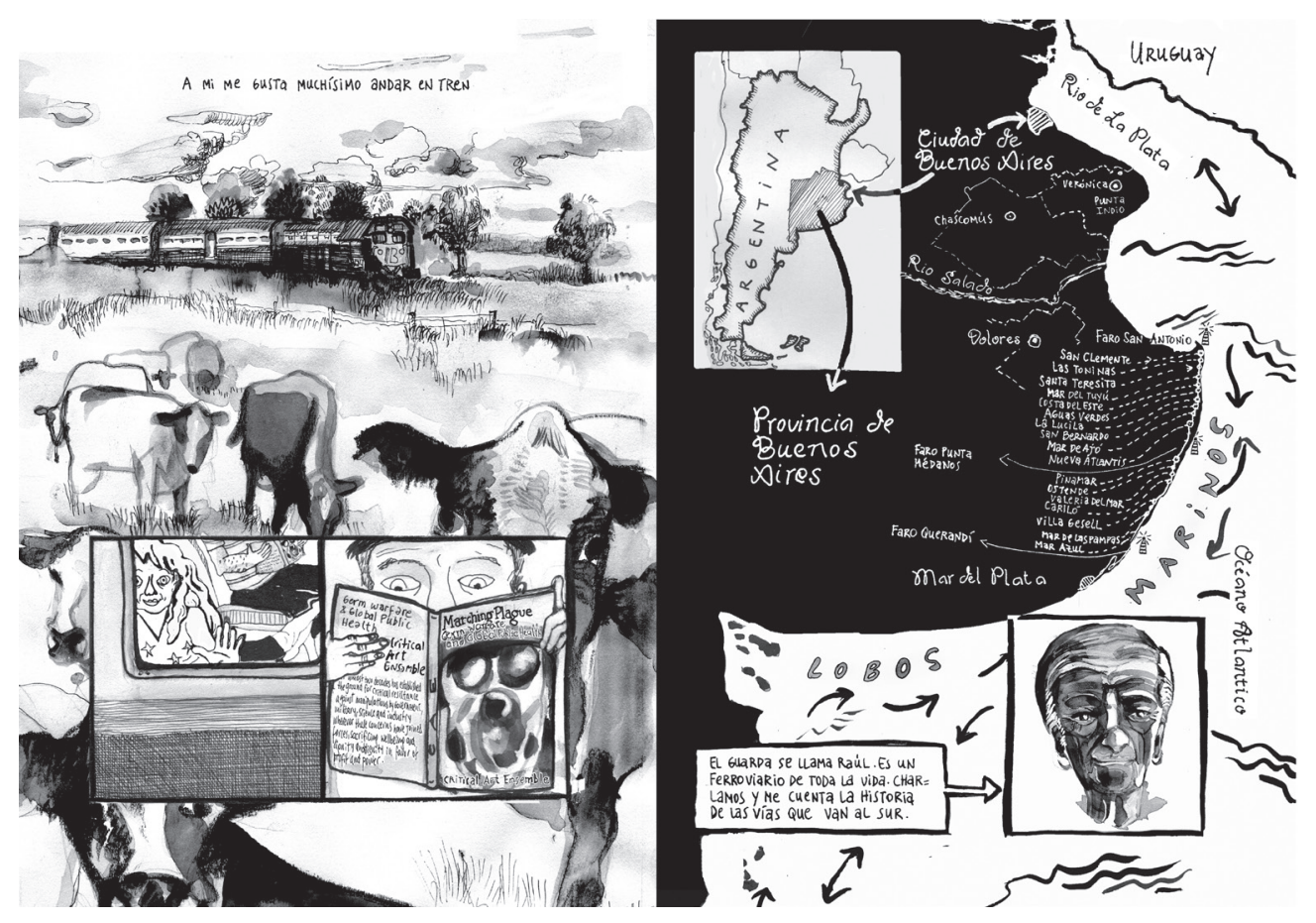

FIG. 2. Blaseotto, A. Vamos a la playa, 2018, pp. 14 y 15.

Concebí las páginas de la novela a pares, es decir, teniendo en cuenta que cuando el lector o la lectora abriera el libro pudiera desplegar ante sí dos momentos complementarios, la página de la izquierda y la de la derecha. «Al principio siempre hay una imagen», otra vez. En mi modo de relatar, es la imagen la que contiene y soporta al

\footnotetext{
${ }^{5}$ Ibid., contratapa.
} 
texto e invita a ver en su interior textos y más imágenes, por donde se mueven los ojos del lector o la lectora. En este par de páginas, catorce y quince, lo que aparece es un retrato panorámico y con detalles de la geografía donde transcurre el primer capítulo de la novela. Una presentación del lugar en tono naturalista desdoblada en dos primeros planos y una vista general (izquierda) confronta al paisaje intelectualizado, el mapa, que geolocaliza la escena y contiene un tercer primer plano (derecha). En la página par vemos «a vista de humano» a los animales observar a los protagonistas, y a la vez, ser mirados por ella. Él mira otra cosa, su mirada se sale de la historia porque está enfrascado en otra, el libro que lee. Por el contrario, en la página impar, el tercer personaje sí mira a los lectores y las lectoras. Mientras que de un lado el mapa representa gráficamente al territorio, el dibujo de paisaje representa su imágen en 3D. El diálogo entre diferentes maneras de mirar es una exploración constante a lo largo de mi trabajo artístico. ${ }^{6}$

En su libro El lugar común, ${ }^{7}$ Silvestri sostiene que la geografía como disciplina ha sido escasamente interrogada en clave de «relación íntima» con la literatura y las artes visuales en Argentina. Originalmente, la geografía como disciplina habría sido una suerte de actividad que amalgamaba relatos de viajes, descripciones gráficas y notas periodísticas. En este trabajo retomo y desarrollo un tono amateur a la vez que subjetivo. La presente novela hace uso de ese tipo de discurso hasta convertirlo en la cadencia que articula el relato. Formada en las reflexiones analíticas acerca de la producción artístico-documental de artistas y teóricos como Alice Creischer o León Ferrari, ${ }^{8}$ practico en mis obras una suerte de transparentización de la voz propia y método de escritura, más en pos de evidenciar mi lugar de enunciación como autora que como alarde alocutivo. Ninguna posición es inocua. Es necesario tomar posición.

Así, en palabras vertidas en la novela:

A mí me gusta muchísimo andar en tren. ${ }^{9}$

Teniendo en cuenta que el trayecto a la playa desde Buenos Aires puede durar entre cinco y ocho horas dependiendo del balneario elegido, es deseable hacerlo más cómodo y seguro que adentro de un auto. Y respirar un mejor aire que el encerrado de un ómnibus. Pero a la playa se accede casi exclusivamente en auto particular o en colectivo de larga distancia. ${ }^{10}$

\footnotetext{
${ }^{6}$ Es el caso, por ejemplo, de mi charla de 2017 titulada «Al sur de la ciudad. Una historia hacia arriba», conferencia performática comisionada por y presentada en el Teatro Nacional Cervantes en el marco del ciclo «Territorios en conflicto», coordinado por Gabriela Massuh y Carlos Gamerro.

7 Silvestri, G. El lugar común. Buenos Aires, Editorial Tiempo Contemporáneo, 1970.

${ }^{8}$ Al respecto, ver el cuerpo de obra producido por los citados artistas. También: Creischer, A., Siekmann, A. y Massuh, G. Schritte zur Flucht von der Arbeit zum Tun / Pasos para huír del trabajo al hacer. Buenos Aires, Cooperativa Chilavert Artes Gráficas, 2004.

9 Blaseotto, A. Op. cit., p. 14.

${ }^{10}$ Ibid., p. 13.
} 
Por eso, esta historia relata cómo es posible llegar a la playa en tren. Aquí aparece el tinte aventurero, aunque sin pretender convertirse en una historia de aventuras. El tipo de páginas como la ya mencionada número 15 , dedicada en su mayor parte a un mapa y a exigirle al lector o la lectora su propio análisis de los gráficos expuestos, interrumpe el ritmo aventurero del ferrocarril e introduce una cantidad de informaciones necesarias para completar el cuadro geográfico. El cual, insisto, es de importancia fundamental para poner en práctica la exhortación de Donald de «Vamos a la playa». ¿Cómo llegaríamos a destino si no pudiéramos visualizarlo? A su vez, estas informaciones, o mejor dicho, datos de la realidad, constituyen el momento previo a lo que sucede inmediatamente después.

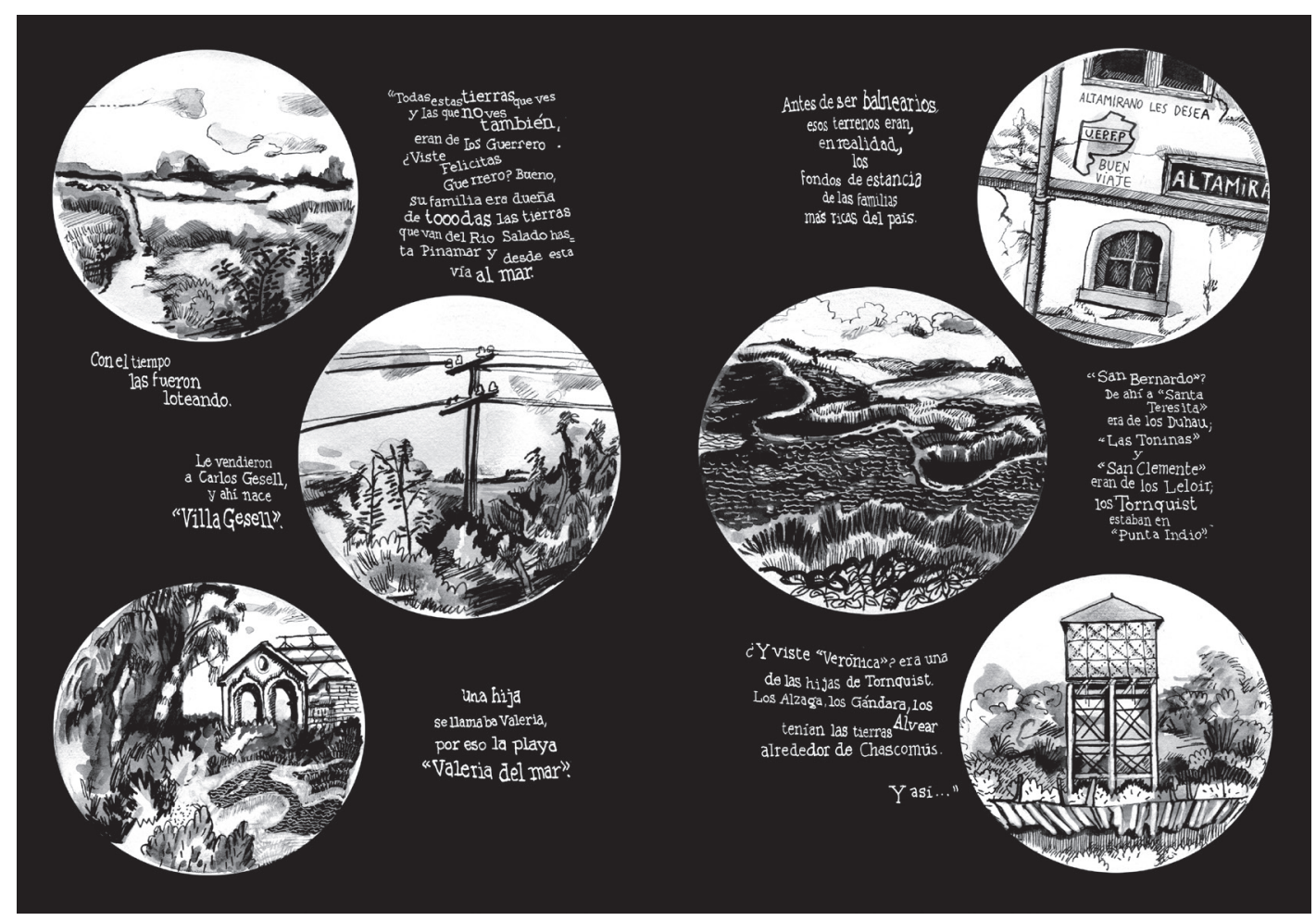

FIG. 3. Blaseotto, A. Vamos a la playa, 2018, pp. 16 y 17.

Aquí estamos ante una doble página que expone fragmentos paisajísticos, los cuales se suceden en el orden que el lector o la lectora elija darle y sostienen un racconto en tercera persona de la historia social que da forma al paisaje natural de la playa a la que los protagonistas se dirigen. ${ }^{11} \mathrm{La}$ voz de la narradora cambia y es asumida por el tercer personaje que fue presentado en la página anterior y personifica al trabajador

${ }^{11}$ Racconto es usado aqui en sentido fuerte, como técnica narrativa que enumera resumidamente una serie de eventos sustanciales para la narración que se está desarrollando en el presente ante el lector o la lectora. 
ferroviario. Raúl existe, no es un personaje inventado, como tampoco su cara es una ideación artística, sino un retrato. Esta operación es subversiva. A contrapelo de como se cuenta tradicionalmente la Historia, decido resaltar la voz del trabajador para narrar la historia de la clase alta.

Otro personaje que apareció en la página anterior es el compañero de ella, el co-protagonista de esta historia. Y lo hace leyendo un libro en inglés del grupo de artistas norteamericanos Critical Art Ensemble, cuyo título, Plaga en marcha. La guerra de los gérmenes y la salud pública global, es una pista para un tema que surgirá más tarde en esta historia, relativo a la alimentación. Cumple, asimismo, con el mandato de transparentización del millieu cultural de los protagonistas.

En cuanto a la puesta en página, elijo presentarla casi como si de cine se tratara. En el sucederse de estas cuatro páginas y el movimiento de planos y ojos que suscitan, también se intercalan las miradas de los sujetos que visionan. Así, el lector o la lectora ve primeramente a la protagonista entrar en diálogo con las vacas, luego adopta el ojo científico de observar una cartografía, para más tarde al dar vuelta la hoja, sumirse en la mirada subjetiva de la protagonista y ver, como si fuera ella, el paisaje. Este aparece representado como horadaciones circulares en un gran plano negro, á la Truffaut. En realidad, no se sabe que se está habitando la mirada de ella hasta pasar a la siguiente página, la 18, donde un plano general permite reconocer la ventana redonda en la puerta del tren, a través de la cual la protagonista ve el campo pasar. Los juegos de movimiento de planos son el correlato de los juegos de movimiento en la historia. Quiénes dicen qué, para qué, y a quiénes.

Al realizar este trabajo, se evidenció cada vez más la necesidad de superponer distintas voces, distintas miradas, cambios de plano frecuentes y, como veremos más adelante, también utilizar distintas técnicas de representación. Creo que la vocación de aunar diferentes perspectivas desde la cual narrar la playa es lo que provoca que en una misma novela confluyan variadas líneas de análisis, y sus consecuentes maneras de llevarlas al papel.

Aunque, si bien es una historia con subhistorias, no intenta ser polifónica. Podríamos decir que es un modo de narrar transversal, pero no «democrático». No cabe todo (todo lo concebible alrededor del tema "playa»), solo lo necesario para exponer una idea y su desarrollo. Este grado de complejidad es el que me llevó a encarar el trabajo como «novela», y no como «historieta», pese a que el debate acerca de la ontología de la novela gráfica queda para otro momento y lugar ya que no es lo que me interesa desarrollar aquí.

\section{La inmobiliaria}

En este capítulo, Vamos a la playa redobla la apuesta por darle contexto social y político a algo tan sencillo y liberador como, suponemos, es irse de vacaciones. También 
es un gran rodeo para llegar a destino y un aplazamiento del deseo por el mar para detenerse en su contrario: la vida inerte del cemento.

Parte de la actual crisis ambiental se debe a la gestión en términos infraestructurales de la vida social. Lejos estamos hoy del paradigma higienista del siglo xIX o, cuanto menos, de la revolución hippie de los años setenta del siglo xx. El contacto con «lo natural» es módico en las ciudades con exclusivos accesos a ammenities en el piso veinte de una megatorre o a paisajes instagrameables como fondo de pantalla, y es mortal en los contextos rurales debido a la contaminación por agrotóxicos tanto de las napas como del aire. El caso de la urbanización descontrolada en el litoral marítimo es lo que me interesa destacar, pues, en Vamos a la playa.

Retomando el texto de la novela:

\begin{abstract}
Hay un ramal que conecta a Buenos Aires con una playa: Mar del Plata. Pero si hay un lugar dónde no queremos ir, es a Mar del Plata. Decidimos entonces viajar todo lo posible en tren y en algún punto del recorrido bajar y empalmar con un micro a cualquier otro balneario. Elegimos bajar del tren en Dolores. Es la población con más habitantes en el recorrido y supusimos que allí habría alguna conexión local a la costa. Digo «supusimos» porque nadie nos aseguró que fuera así. En internet no figuraba. Tampoco nadie nos atendió el teléfono en ninguna estación de Dolores o Buenos Aires. Ni en San Clemente u otra playa. La planificación de un viaje alternativo al absolutismo de la nafta y el hormigón armado se había transformado en una aventura en sí misma. ${ }^{12}$
\end{abstract}

Las cuatro páginas a analizar a partir de aquí condensan observaciones sociológicas y estéticas acerca del paisaje inmobiliario que desborda las ciudades e invade pueblos del interior de la provincia hasta llegar al mar, así como una lectura en clave histórica del proceso que lo posibilitó. Recurro para ello a evidencias visuales tales como fotografías propias e históricas, cuadros y periódicos.

La constante es la caminata de los dos protagonistas, quienes, arribados por tren a Dolores, atraviesan el pueblo para tomar el colectivo hasta la playa. Ella y él caminan durante toda la novela. Las conversaciones que mantienen se sostienen en el tiempo peripatético de un andar que casi no puede relajarse. Casi nunca hacen «nada» ni «vacacionan» en sentido estricto. Y cuando sí lo logran, se termina la historia.

En la página par comienza esta historia en un sentido alejado de lo bucólico. Los protagonistas se ven confrontados causalmente en su recorrido a dos formas arquitectónicas diametralmente opuestas de organización del tiempo libre común. Por un lado, un complejo deportivo público y, por el otro, un parque temático privado. Ambos edificios conviven en uno y otro extremo de los cien metros que diseñan un mismo espacio en los catastros urbanos argentinos. Los dos espacios

12 Blaseotto, A. (2018). Op. cit., p. 25. 
propositivos escenifican, a su vez, diferentes épocas. El segundo, sin caer en la nostalgia, puede ser visto como una claudicación histórica en lo que hace a derechos adquiridos, como el derecho al esparcimiento y la gratuidad del mismo. Ella va a resumir este proceso en una burbuja de diálogo: «la privatización de la alegría del pueblo». ${ }^{13}$
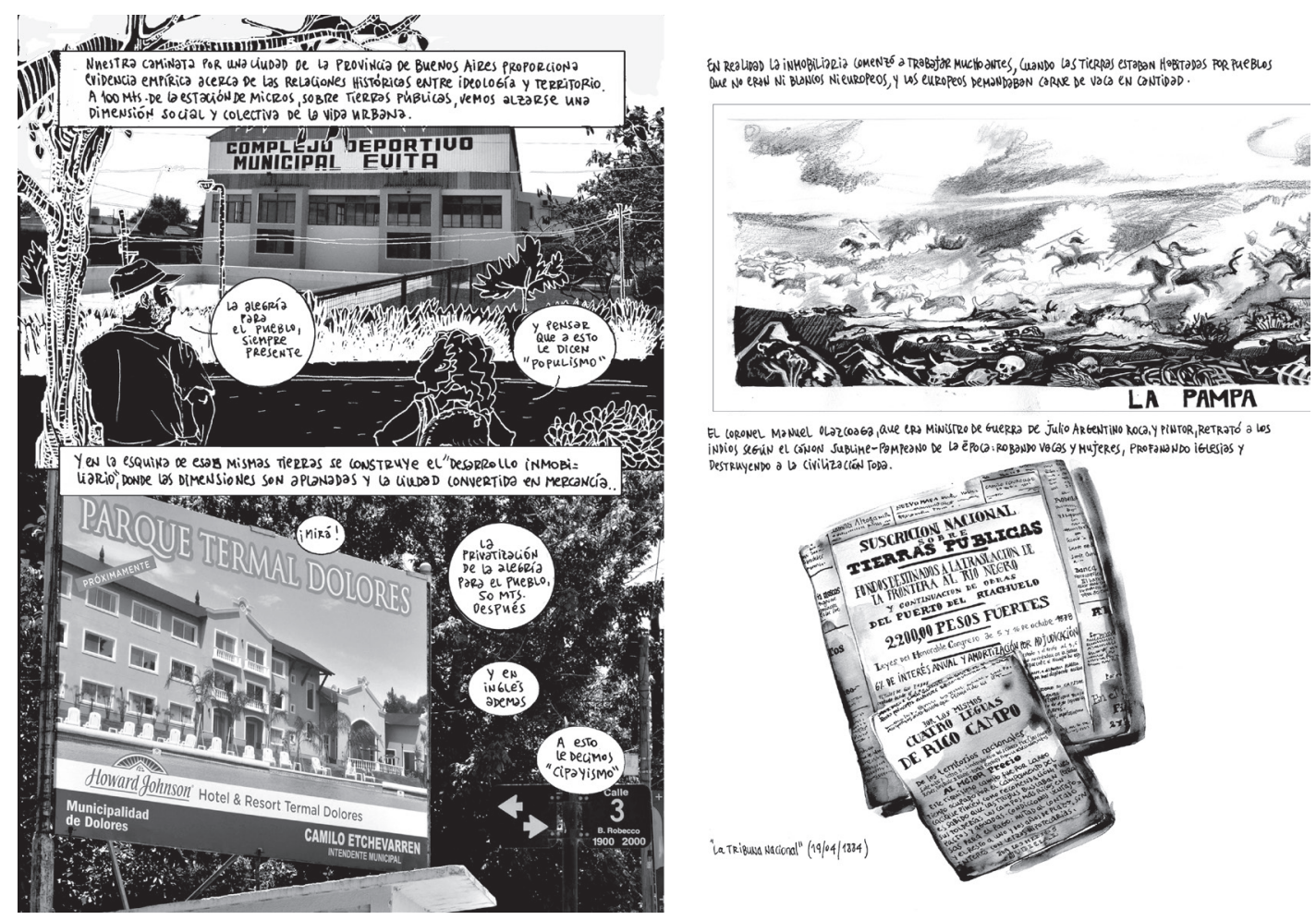

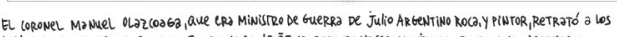

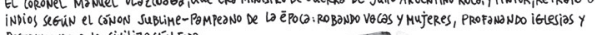
Destruyendo a la civilizacín Topa.

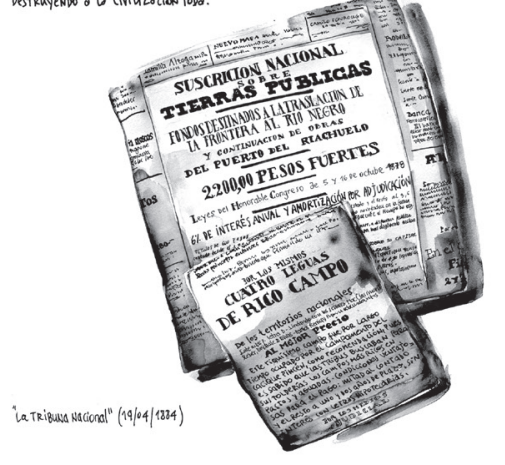

FIG. 4. Blaseotto, A. Vamos a la playa, 2018, pp. 44 y 45.

En trabajos anteriores he desarrollado el concepto de subjetividad baldosa para estudiar las significaciones e implicancias de la urbanización: ${ }^{14}$

A la voluntad de cementar todo espacio concebido como un vacío, de completarlo con hormigón, luces, rejas, alarmas, y de darle forma con seguridad, cámaras y garajes, la denominamos «subjetividad baldosa». La misma es una actitud vertical y excluyente, una manera de conseguir máximo lucro en todo lugar. ${ }^{15}$

13 Ibid., p. 44.

${ }^{14}$ El concepto aparece por primera vez en Blaseotto, A. Negocios inmobililiarios, clase y naturaleza en colores. Cómo construir un museo. Buenos Aires, Ediciones La Dársena. Unprobema+, 2013.

15 Blaseotto, A. «Una historia de abajo hacia arriba», en Merlinsky, G. y Serafini, P. Arte y ecología politica. Buenos Aires, CLACSO, 2021.p. 61. 
Si bien en esta novela la subjetividad baldosa no aparece con su nombre propio, es una de las líneas argumentativas que articula la historia. Porque Vamos a la playa tiene que que ver no solo con la playa, sino con lo que de playa queda en un mundo dominado por la economía de mercado y la obsoletización permanente de la concepción «Estado de Bienestar». La subjetividad baldosa aplana tanto las protuberancias como los vacíos urbanos, las autonomías espaciales, así en las ciudades como fuera de ellas:

\begin{abstract}
Según el pensamiento político-económico hegemónico actual habría dos clases de vacíos que desembocan conjuntamente en un estuario de prometedoras posibilidades urbanas «modernas» [...]: el espacial y el simbólico. Los espacios verdes urbanos (y periurbanos) como plazas y parques, heredados de la concepción higienista urbana del siglo XIX, sumados a los de la imprevisión y el abandono, como separaciones, baldíos y reservas ecológicas, son vistos por ojos codiciosos como faltos de materialidades y carentes de valor. En una época de urbanización plena, de plena imagen pública erizada de escenas de construcción como visibilización del trabajo y de gobiernos vinculados a las empresas constructoras surge la pregunta: ¿qué hacer con territorios privados de arquitecturas y desaprovechados rentísticamente? ${ }^{16}$
\end{abstract}

El espacio geográfico «playa» puede y, de hecho, está siendo interpretado como «falto de materialidades y valor». Una vez saturada la gran ciudad, el broker inmobiliario se traslada a territorios vírgenes donde seguir produciendo valor. Las mismas edificaciones son construidas al borde del mar, las mismas necesidades son trasladadas del entramado urbano al cimiento de arena, idénticos problemas de contaminación lumínica, sonora y sanitaria mudan a distinto clima:

La subjetividad baldosa acciona por etapas: desmaleza, entuba, aplana; arranca, empuja, apisona; proyecta una fantasía y la yergue. Su dominio es hegemónico y transnacional, atraviesa globalmente a las grandes ciudades y pareciera que también es inmortal. ${ }^{17}$

Traer a colación la cuestión de la cementización y verticalización de la experiencia habitacional en un trabajo que desde su título alude a otra cosa que me resulta fructífera para establecer el planteo acerca de cómo se está construyendo la vida urbana (y periurbana). En páginas siguientes este contraste vuelve a aparecer, así como el juego entre el dibujo y la fotografía. La página 68 es un ejemplo de ello.

Se espera que la playa sea un espacio otro, distinto a lo urbano. Se fantasea con lo asilvestrado, la precariedad expresada en los elementos naturales, pero no es así. Ahora se puede ir a la playa para vivir la experiencia de una ciudad, podemos visitar San Clemente como si estuviéramos en Miami. Aunque, después de todo, ¿no es precisamente esa deslocalización nuestra experiencia histórica como nación ex-colonia espa-

${ }_{16}$ Ibid., p. 61.
${ }^{17}$ Ibid., p. 69. 
ñola? ¿No nació Mar del Plata, madre de todas las playas, como un vástago no reconocido de Brighton, Gran Bretaña?

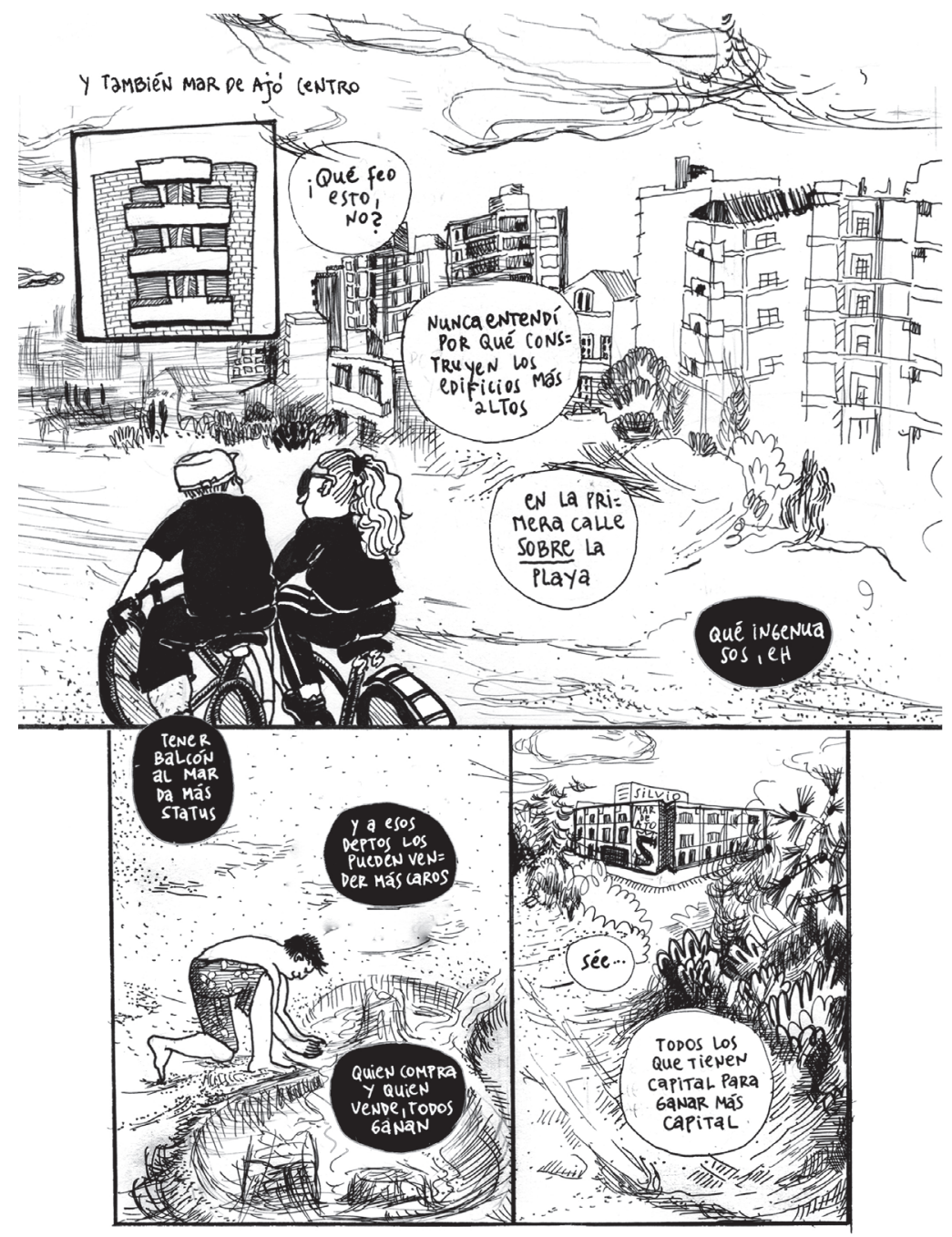

FIG. 5. Blaseotto, A. Vamos a la playa, 2018, p. 68.

En libros ya clásicos acerca de la playa asistimos a descripciones ensoñadas y optimistas:

Mar del Plata es hoy calificada expresión del genio creador de los argentinos y habiendo superado su centenario, ocupa un puesto de vanguardia entre las grandes ciudades. Ofrece sin pausa transformaciones integrales y el espectáculo maravilloso de su evolución y su progreso. $^{18}$

18 Barili, R. Historia de mar del Plata. Buenos Aires, Plus Ultra, 1991, p. 15. 
También a otras, más interesantes aún por sus precisiones sociohistóricas:

La real existencia histórica de Mar del Plata tiene su orígen en el proceso de acumulación primitiva de los medios de producción a partir de la revolución burguesa de 1810, es decir, en el reparto de la terra, y a continuación en la consolidación de la primera forma rudimentaria de capitalismo agrario argentino: la producción de carne salada o tasajo. ${ }^{19}$

Vamos a la playa presta atención, como se dijo, a las consideraciones estéticas, históricas, geograficas y también políticas del paisaje catalogado como "playa».

Otro aspecto de la página 42 que me parece significativo para este análisis es que está atravesada enteramente por la política en clave ideológica. El primer edificio lleva el nombre de la principal referente mujer de los derechos de las clases más humildes en el país, Eva Duarte de Perón; el segundo porta el desvaído sustantivo del pueblo homónimo, con subtítulo en otro idioma y referencia a un nombre propio con sonido de shampoo: Parque Termal Dolores, Howard Johnson Hotel and Resort termal Dolores. $\mathrm{El}$ «Complejo Deportivo Municipal Evita» encarna una política de extracción nacional y popular, y funciona desde hace cincuenta años. El parque termal es la alzada de los negocios inmobiliarios transnacionales. La tensión que vectoriza el territorio físico y simbólico es lo que fascina a los dos protagonistas y los impulsa a seguir caminando y reflexionando a lo largo de todo el libro. Allí, ante ellos, «aparecen» los disparadores. Como el dibujo del cuadro de la página impar, la 45, visitado en el Museo Histórico de Dolores, el cual representa el mismo lugar pero en una época muy anterior al edifico público y a la promesa privada.

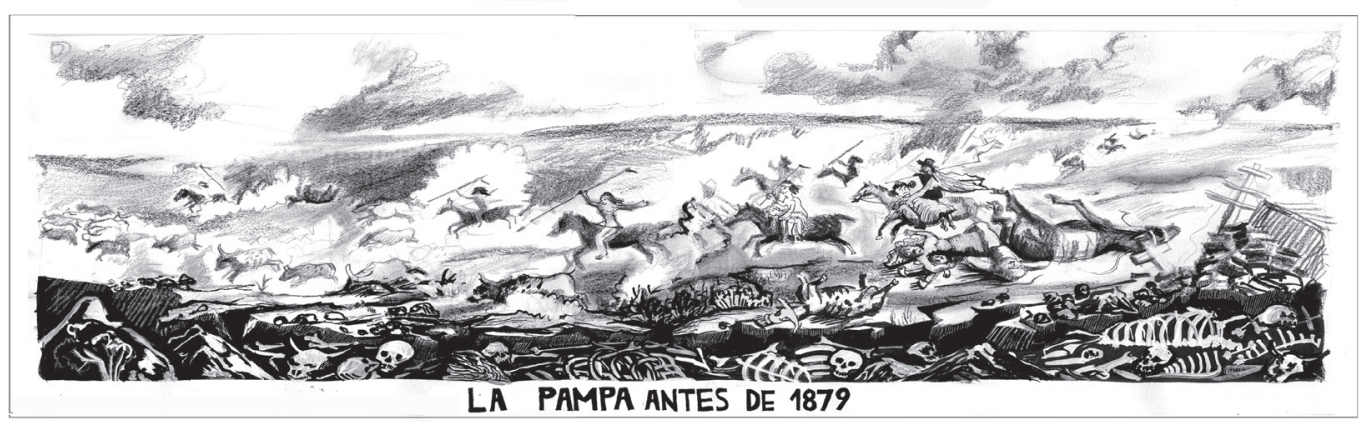

FIG. 6. Blaseotto, A. Vamos a la playa, 2018, detalle de la imagen reproducida en pp. 45 y 46.

La inmobiliaria había comenzado a trabajar mucho antes, en el siglo xIx, cuando las tierras estaban habitadas por pueblos que no eran ni blancos ni europeos, y los

19 Sebreli, J. J. Mar del Plata, el ocio represivo. Buenos Aires, Editorial Tiempo Contemporáneo, 1970, p. 21. 
europeos demandaban carne vacuna en cantidad. Esta viñeta (FIG. 6) reproduce la acuarela realizada por el militar Manuel Olascoaga, La Pampa antes de 1879. Dividida en dos y desplegada en las páginas 45 y 46, la imagen funciona como una versión patriótica del Naturgemälde alemán. En ella vemos a los indios conduciendo ganado vacuno por sobre un campo sembrado de cadáveres. En el horizonte queda solo el viento y el humo de poblados incendiados. Desde el punto de vista de Olascoaga, este sería un retrato realizado siguiendo el canon sublime-pampeano de su época: los indios roban las propiedades de los blancos, sus vacas y mujeres; profanan sus iglesias y destruyen, así, a la civilización en su conjunto.

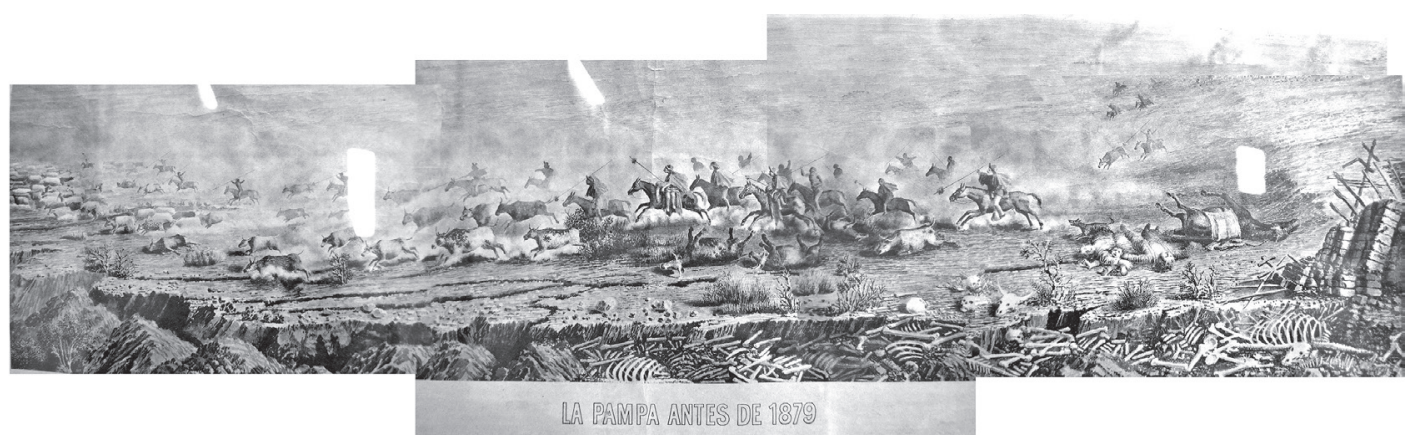

FIG. 7. Fotografía, archivo personal de Azul Blaseotto. Toma directa de la acuarela enmarcada y realizada por Manuel de Olascoaga y exhibida en el Museo Histórico de Dolores, 2014.

Olascoaga fungió como ministro de guerra durante la presidencia de Julio Argentino Roca, y fue uno de los coroneles en la mal llamada "conquista del desierto», donde desierto es un eufemismo para mesetas, bosques y cuencas habitadas. En paralelo desarrolló una actividad como pintor y topógrafo aficionado, donde lo artístico (por impreciso y libre) prevaleció sobre lo científico-topográfico, y lo militar (por jerárquico y autoritario) dominó lo artístico. Este militar condensó en una sola imagen muchos fenómenos «naturales»: la tragedia de la raza blanca sobre un escenario chato y monótono; lo ominoso a ser extirpado y la promesa de un horizonte vacío para rellenar con inversiones. Extranjeras, naturalmente. Lo constatan, una comprobación entre muchas que aparecen en la novela, los protagonistas ante el cartel Howard Johnson Hotel and Termal Resort Dolores.

Al dar vuelta a la página, se completa la imagen de Olascoaga. Al igual que su precedente, la 46 se resuelve mediante «imágenes fijas», donde el cuadro funciona como viñeta y bajo él, otro método de representación: una foto histórica, aunque dibujada. Esta imagen también encarna una viñeta, pero entre ella y la de arriba no hay secuencialidad. Por oposición, la página 47 sí se resuelve en una secuencia conformada por dibujos y fotografías cerrando el capítulo. Allí él le pregunta a ella qué hace mientras esperan al colectivo a la playa. Ella le responde que dibuja. Dibuja lo que vive: «Dibu- 
jo para no olvidarme». Como en Olascoaga, y en otras y otros artistas, los cuadros de situación, los «cuadros de naturaleza», los cuadros que cuentan historias buscan resguardar memorias determinadas. Pero no solo eso.
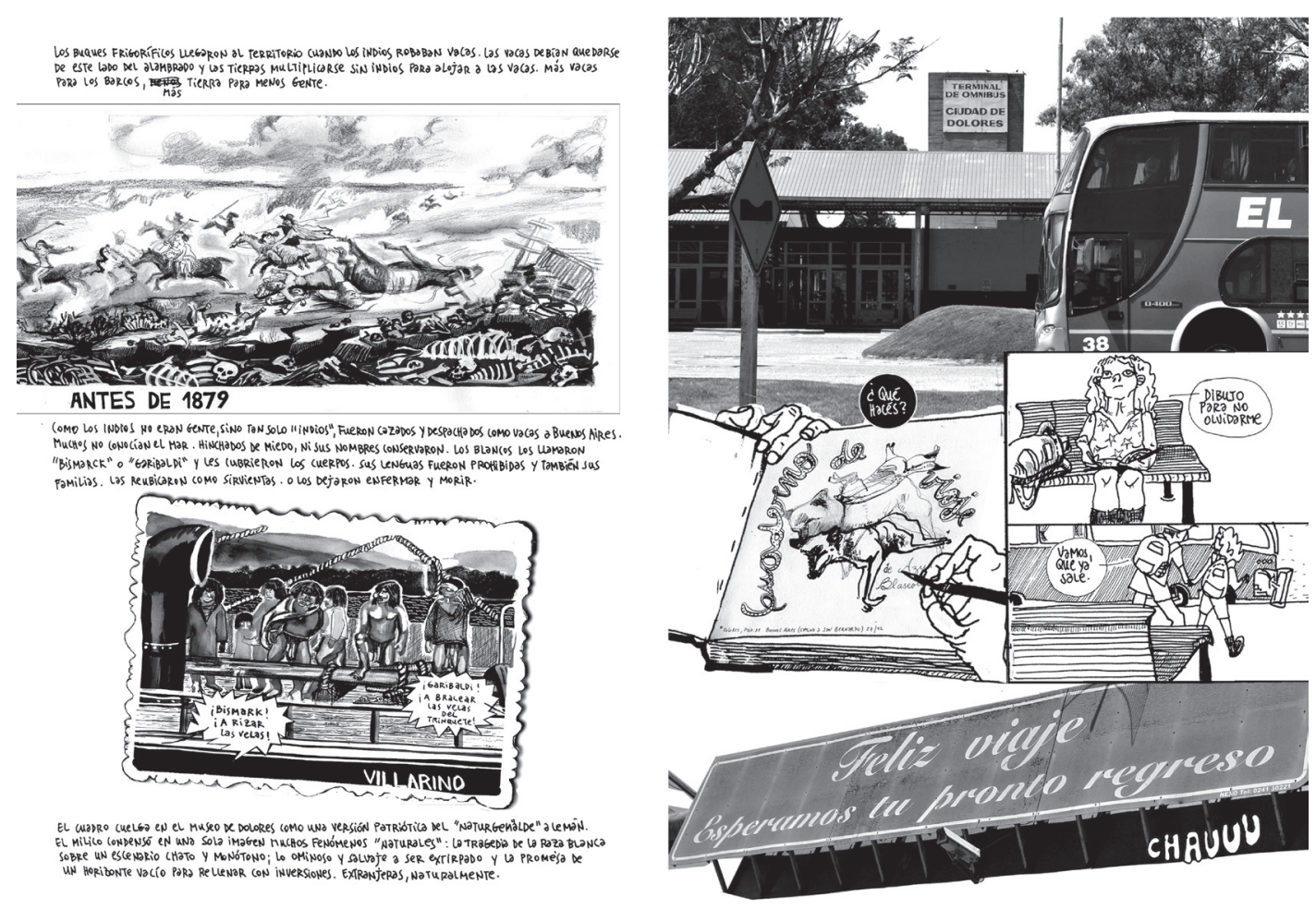

FIG. 8. Blaseotto, A. Vamos a la playa, 2018, pp. 46 y 47.

Malena Mastricchio es geógrafa y en una crítica sobre Vamos a la playa vinculó el aspecto social de la práctica geográfica con la memoria estética del territorio:

Berger comienza su libro afirmando que «dibujar es descubrir» y efectivamente el dibujo de Azul muestra un acto de descubrimiento. Descubre la espacialidad bonaerense: ese conjunto de prácticas simbólicas y materiales desplegadas por las sociedades a lo largo del tiempo para apropiarse de un espacio. Relata y reconstruye la historia territorial de la provincia de Buenos Aires con la palabra y con la imagen. El libro narra la multiplicidad, la diversidad y la desigualdad de las prácticas sociales que se conjugan para construir el espacio geográfico: la conquista de la Pampa; la política de Juárez Celman y sus consecuencias para la clase obrera argentina... Historia territorial que permanece, hasta nuestros días, objetivada en el espacio. ${ }^{20}$

20 Mazitelli Mastricchio, M. «Vamos a la playa. De Azul Blaseotto», en Revista Guay (21 de marzo de 2021). Disponible en: http://sedici.unlp.edu.ar/bitstream/handle/10915/116728/Documento completo.12358\%20-\%20Mazzitelli\%20Mastricchio.pdf-PDFA.pdf?sequence=1\&isA$\underline{\text { llowed }=y}$ 


\section{El mar}

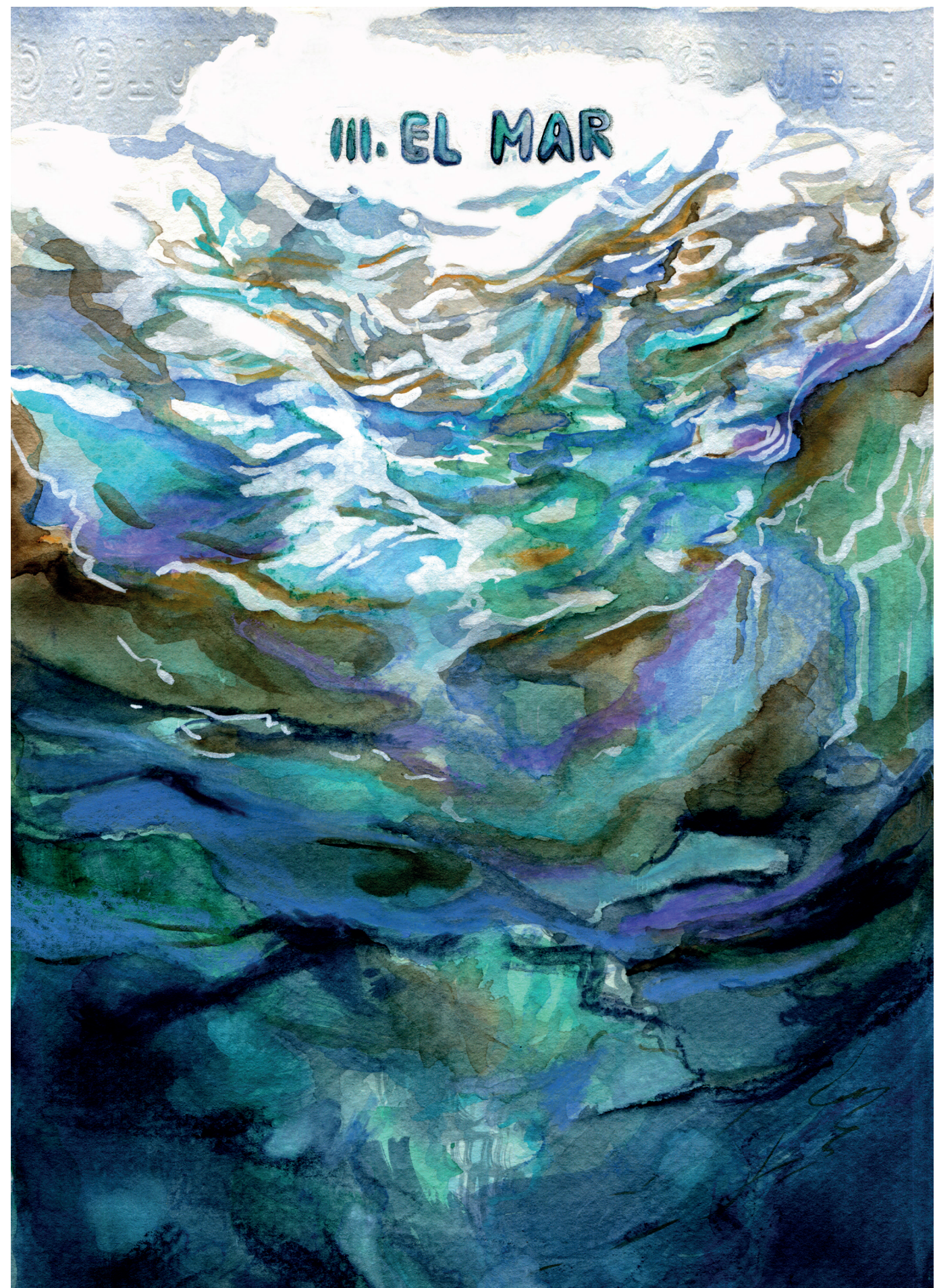

FIG. 9. Blaseotto, A. 2016. Acuarela. 
Lo inconmensurable. Lo indominable. Lo nunca-igual-a-sí-mismo. Ese es el destino buscado en una playa. Acceder a él le implicó a su autora dibujar un libro que encierra la acción mínima de salir de la ciudad en busca de otra cosa. A los protagonistas les llevó cincuenta de las 128 páginas llegar hasta allí.

El final de la novela da en sus últimos dos capítulos, «El mar» $\mathrm{y}$ «Los indios y los alemanes» un giro en su línea argumentativa. A la dimensión sociohistórica expuesta hasta ese momento, decidí profundizar la dimensión personal y subjetiva de las dos personas protagonistas, que son expuestas en detalle, y además se incorporan sus amistades. El retrato se enfoca entonces en el cotidiano playero de la vida de todos estos personajes. En ese lugar, la playa, dibujada como dimensión de la reunión y la amistad (FIG. 10, 11 y 12), se festeja y se festeja con otros y otras.

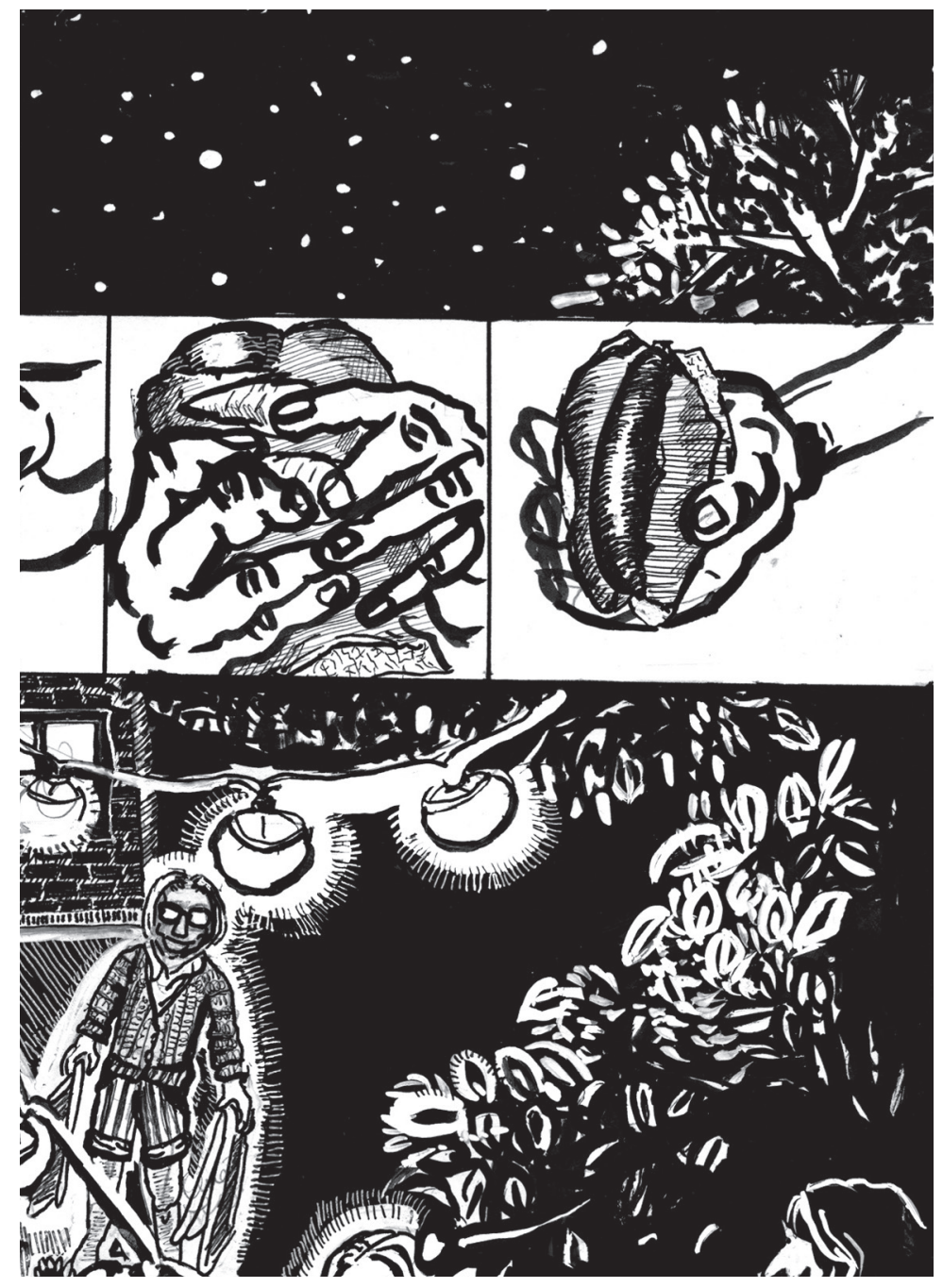

FIG. 10. Blaseotto, A. Vamos a la playa, 2018, p. 118. 
La playa reivindicada en esta novela es la que se construye como sinónimo de libertad, de reencuentro, de actividades lúdicas en las que se invierte lo más preciado: el tiempo. Tiempo de espontaneidad y alegría porque sí. En épocas de neoliberalismo, de aislamiento preventivo y espectacularización de la vida privada en redes electrónicas monitoreadas por intereses extractivos, jugar, cantar, cocinar, despojarse de ropas y nadar instituyen prácticas privilegiadas. No se ejercita el canto comunitario como resabio bippie, sino como práctica política, aúténtica toma de posición de rebelarse contra la cementización de la vida. Vamos a la playa no es una mera cita a la canción pop, tampoco una incitación a la nostalgia. Es una invitación a imaginar, ya que «al principio siempre hay una imagen», $\mathrm{y}$ a habitar los territorios de otra manera que la gestionada por la hegemonía del capital globalizado.

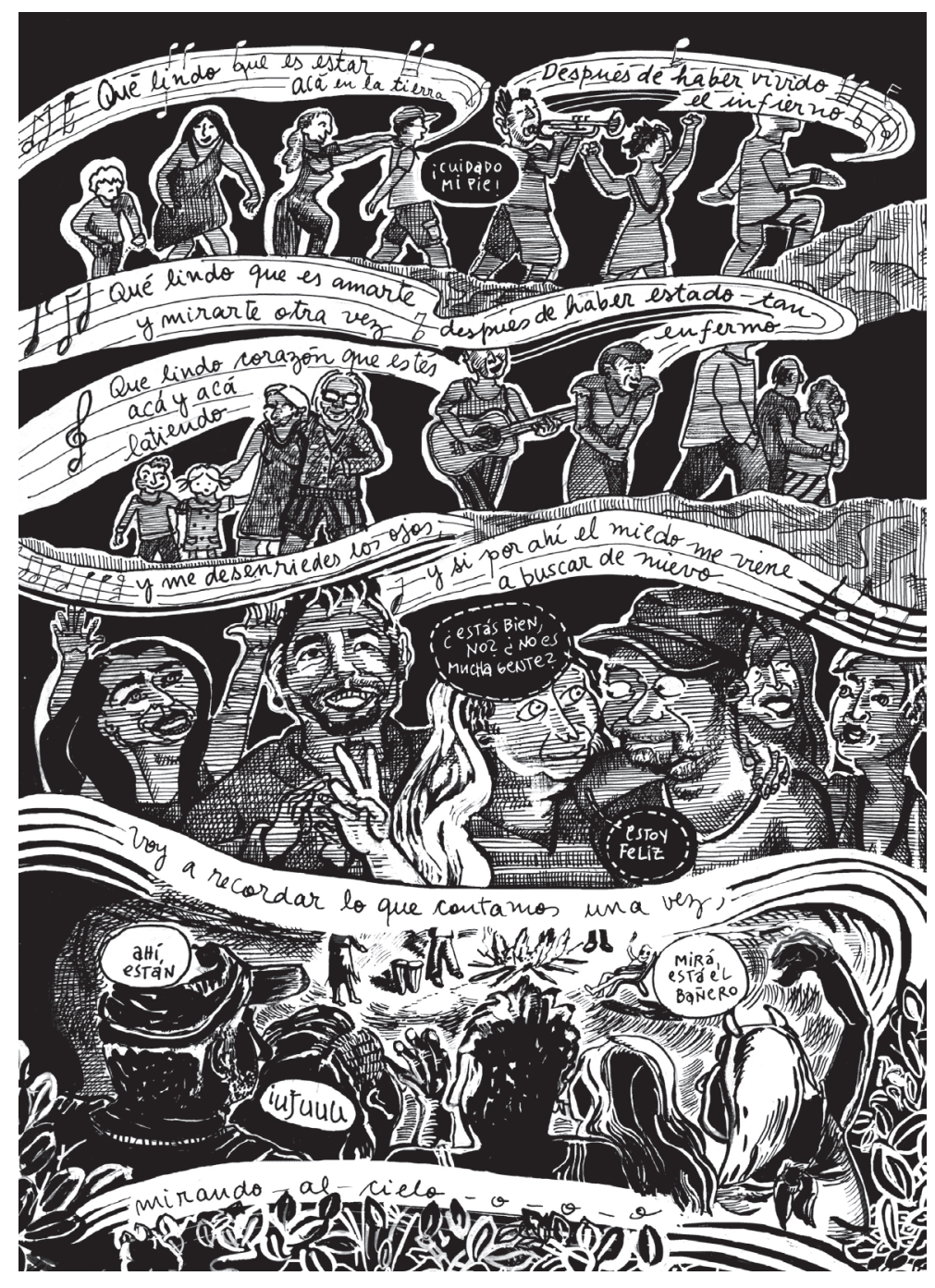

FIG. 11. Blaseotto, A. Vamos a la playa, 2018, p. 119. 


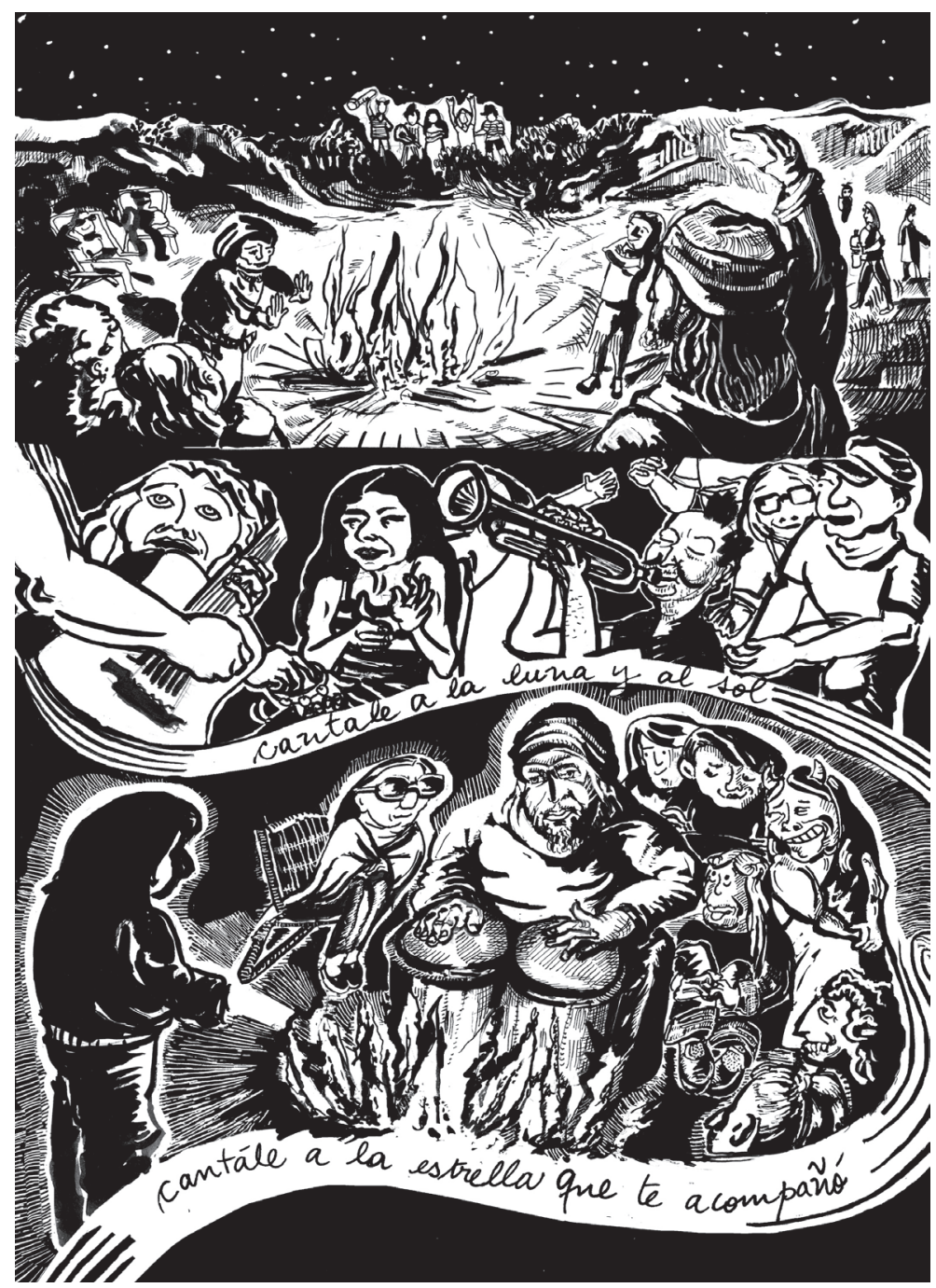

FIG. 12. Blaseotto, A. Vamos a la playa, 2018, p. 120. 


\section{Bibliografía}

Aliata, F. y Silvestri, G. El paisaje como cifra de armonia. Buenos Aires, Nueva Visión, 2001.

BArili, R. Historia de mar del Plata. Buenos Aires, Plus Ultra, 1991.

Blaseotto, A. Negocios inmobililiarios, clase y naturaleza en colores. Cómo construír un museo. Buenos Aires, Ediciones la Dársena. Unprobema+, 2013.

—Vamos a la playa. Temperley, Tren en Movimiento, 2018.

— «Una historia de abajo hacia arriba», en Merlinsky, G. y Serafini, P. Arte y ecología politica. Buenos Aires, CLACSO, 2021.

Creischer, A., Siekmann, A. y Massuh, G. Schritte zur Flucht von der Arbeit zum Tun / Pasos para huir del trabajo al hacer. Buenos Aires, Cooperativa Chilavert Artes Gráficas, 2004.

Mazitelli Mastricchio, M. «Vamos a la playa. De Azul Blaseotto», en Revista Guay (21 de marzo de 2021). Disponible en: http://sedici.unlp.edu.ar/bitstream/ handle/10915/116728/Documento completo.12358\%20-\%20Mazzitelli\%20 Mastricchio.pdf-PDFA.pdf? sequence $=1$ \&isAllowed $=y$

Mitchell, W. J. T. Landscape and power. Chicago, University of Chicago, 1994.

Sebreli, J. J. Mar del Plata, el ocio represivo. Buenos Aires, Edhasa, 2011.

Silvestri, G. El lugar común. Buenos Aires, Editorial Tiempo Contemporaneo, 1970.

TNA / Díaz, F. et al. Territorios en conflicto. Buenos Aires, Teatro Nacional Cervantes, 2017. 